\title{
Quantifying differences in biodiversity between a tropical forest area and a grassland area subject to traditional burning
}

\author{
Grace Nangendo, Alfred Stein", Martien Gelens, Alfred de Gier, Robert Albricht \\ International Institute for Aerospace Survey and Earth Sciences (ITC), P.O. Box 6, 7500 AA Enschede, The Netherlands
}

Received 19 September 2000; received in revised form 16 March 2001; accepted 10 May 2001

\begin{abstract}
Mosaics of natural forest and grassland tracts in sub-Saharan Africa provide differences in woody species biodiversity. These mosaics are of considerable interest as they are a major biodiversity bank. Their richness is felt to be threatened, for example by local burning. This study focuses on the impact of burning on biodiversity in the Budongo Forest Reserve in Uganda. Woody species at different development stages are compared between a forest stratum and the adjacent grassland stratum. Spatial variability of biodiversity indices is analysed within and between these strata, using statistical and geostatistical analysis methods. The forest stratum shows a higher woody species diversity on a per plot basis. With overall species diversity calculations, however, the grassland stratum has a higher woody species variability than the forest. For the long-term preservation of woody species diversity in this landscape, it is necessary to reconsider and adjust current management practices to maintain (fire) disturbances. (C) 2002 Elsevier Science B.V. All rights reserved.
\end{abstract}

Keywords: Biodiversity; Shannon index; Tropical forest; Grassland; Burning; Spatial variability; Uganda

\section{Introduction}

Worldwide, in 1994, nearly 5400 animal species and more than 26,100 plant species were threatened (Dallmeier, 1998). The fundamental goal of biodiversity conservation is to support sustainable development by protecting and using biological resources in ways that do not diminish the world's variety of species or destroy important habitats or ecosystems (Reid et al., 1993). Uganda, located in a zone of overlap between ecological communities of the dry East African savannas and those of the West African rain forests, contains more species than almost any other country in Africa (Howard et al., 1998a). Seven

\footnotetext{
* Corresponding author. Tel.: +31-53-4874444; fax: +31-53-4874400.

E-mail address: stein@itc.nl (A. Stein).
}

major bio-geographic regions exist in Uganda, each with a distinct flora and fauna, whereby each biogeographic region contains more than 50\% endemics.

In response to increasing threats to biodiversity, forest management in Uganda has shifted from emphasis on timber production to biodiversity conservation. Within this context, nationally a network of sites covering $20 \%$ of the natural forest land has been assigned the status of 'forest nature reserve' or 'core forest area', where the focus of management is primarily on the protection of habitats to conserve biodiversity (Howard et al., 1998b).

Grassland-forest mosaics are common in Uganda. Many of the grassland areas are annually burned by pastoralists and hunters. Traditionally, foresters in Uganda, with their preoccupation with timber production of the past, consider this burning as a threat to forest expansion and forest quality and would qualify 
these grassland/forest mosaics as 'mismanaged' or 'valueless'. Little attention has, therefore, been given to the study of their species and the species interactions between these areas. There is evidence that fire may play a beneficial role in some ecosystems (Chandler et al., 1983; McDougall, 1989; Morgan and Lunt, 1999; Oesterheld et al., 1999). Natural savannas, e.g., are now considered to benefit from fire, the majority having been created and maintained by human induced fires. Periodic occurrence of fire ensures the continued existence of fire-dependent ecosystems. If fire occurs with sufficient regularity and intensity, ecosystems can be stabilised for millennia (Chandler et al., 1983; Forman and Godron, 1986; Paterson, 1991).

This study aims to identify and quantify woody species diversity and its spatial variation at different scales in a relatively undisturbed forest area and the adjacent grassland area. Indices are used for identification and quantification of biodiversity. At the highest scale, statistical procedures quantitatively compare these indices between the strata. At the finest scale, geostatistical procedures study the spatial variability within the two strata. Through this study a more solid basis for the development of (forest) management systems appropriate for biodiversity conservation is created, which in turn may lead to the reconsideration and adjustment of the present (forest) management systems. The study area is located within the Budongo Forest Reserve in the north-west of Uganda.

\section{Materials and methods}

\subsection{Study area}

Budongo Forest Reserve is located in the northwestern part of Uganda between $1^{\circ} 35^{\prime}-1^{\circ} 55^{\prime} \mathrm{N}$ and $31^{\circ} 18^{\prime}-31^{\circ} 42^{\prime} \mathrm{E}$ (Fig. 1) and receives $1397-1500 \mathrm{~mm}$ rain annually in 100-150 days. It covers an area of 82,530 ha, making it Uganda's largest forest reserve. The vegetation of the reserve is a rich mixture of tropical high forest (with a large population of mahoganies), woodlands and grasslands that are thought to be capable of supporting forest. Forest covers $53.7 \%$ and woodland and grassland $46.3 \%$ of the area. Budongo Forest Reserve is of exceptional importance for biodiversity, containing approximately 465 species of trees and shrubs, 366 bird species, 289 butterfly species and 130 species of large moths.

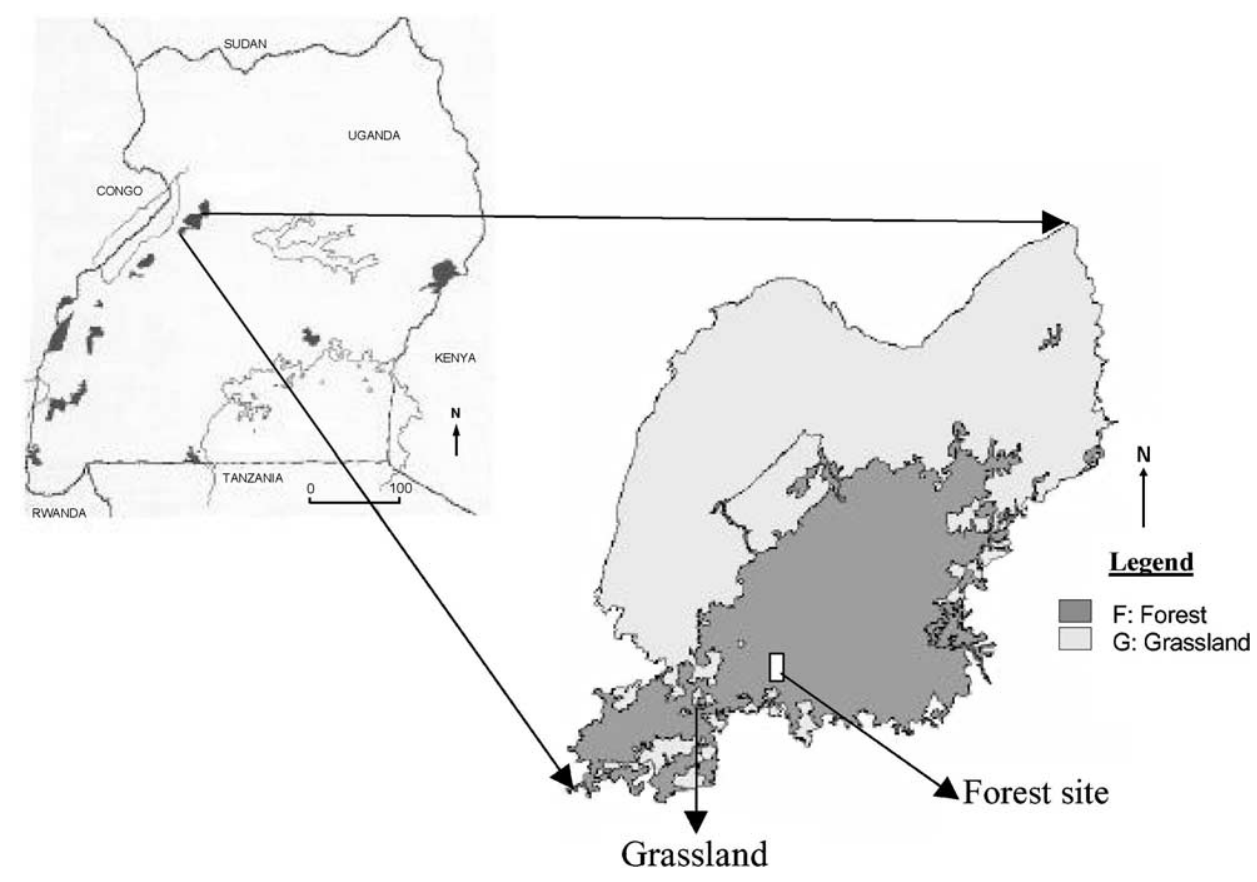

Fig. 1. Map showing the location of Budongo Forest Reserve and the data collection sites. 
The local population in the Budongo Forest Reserve area is of a mixed composition. People from other parts of Uganda and from Sudan and Congo have settled and joined the original inhabitants, the Banyoro, in the villages around the forest (Langoya et al., 1998). Some of the immigrant tribes practice game hunting as a means of providing supplementary protein to their family's diet. An important tool in hunting is the seasonal burning of grasslands. The cover type in the grassland areas varies with variation in fire frequency. The areas that are burned regularly have a sparser tree and shrub cover than those that are burned less frequently. The changes in tree and shrub cover correspond with changes in the floristic composition of the area (Connell and Slatyer, 1977; Chandler et al., 1983).

\subsection{Measuring biodiversity}

Biodiversity concerns spatial variability of species and individuals within ecosystems. In this study biodiversity is defined as the variability in space among living organisms and the ecological complexes of which they are part; this includes diversity within species, between species and of ecosystems (Parviainen and Päivinen, 1998). We apply the Shannon index $\left(H^{\prime}\right)$ as a measure of species abundance and richness to quantify diversity of the woody species. This index takes both species abundance and species richness into account, is sensitive to changes in the importance of the rarest classes (Heusèrr, 1998) and is the most commonly used index (Kent and Coker, 1992). For any quadrat it is calculated as

$H^{\prime}=-\sum_{i=1}^{s} p_{i} \ln p_{i}$

where $s$ equals the number of species and $p_{i}$ equals the ratio of individuals of species $i$ divided by all individuals $N$ of all species. The variance of $H^{\prime}$ is calculated by

$\operatorname{var} H^{\prime}=\frac{\sum p_{i}\left(\ln p_{i}\right)^{2}-\left(\sum p_{i} \ln p_{i}\right)^{2}}{N}+\frac{s-1}{2 N^{2}}$

and a $t$-statistic to test the significant differences between two quadrats or samples as

$t=\frac{H_{1}^{\prime}-H_{2}^{\prime}}{\sqrt{\operatorname{var} H_{1}^{\prime}+\operatorname{var} H_{2}^{\prime}}}$ where $H_{j}^{\prime}$ is the Shannon index of sample $j, j=1,2$. Degrees of freedom for this test are equal to

d.f. $=\frac{\left(\operatorname{var} H_{1}^{\prime}+\operatorname{var} H_{2}^{\prime}\right)^{2}}{\left(\operatorname{var} H_{1}^{\prime}\right)^{2} / N_{1}+\left(\operatorname{var} H_{2}^{\prime}\right)^{2} / N_{2}}$

where $N_{1}$ and $N_{2}$ are the number of individuals in samples 1 and 2, respectively (Magurran, 1988). Notice that the degrees of freedom do not necessarily give an integer value, a feature commonly observed in testing with unequal sample sizes and variances.

In addition, we consider the Simpson index $(D)$, a measure of species dominance, and the ShannonWiener index $(E)$, a measure for evenness of spread. The Simpson index is defined as

$D=\sum_{i=1}^{s}\left(\frac{n_{i}\left(n_{i}-1\right)}{N(N-1)}\right)$

where $n_{i}$ is the number of individuals in the $i$ th species and $N$ equals the total number of individuals. As biodiversity increases, the Simpson index decreases. Therefore, to get a clear picture of species dominance, we used $D^{\prime}=1-D$. The Shannon-Wiener index is defined as

$E=\frac{H^{\prime}}{H_{\max }}=\frac{-\sum_{i=1}^{s} p_{i} \ln p_{i}}{\ln s}$

where $H_{\max }$ is the natural logarithm of the total number of species. Finally, we consider Fisher's $\alpha$, defined as

$F_{\alpha}=\frac{(N-s) / N}{N}$

Notice that the distribution of individuals over the different species does not affect $F_{\alpha}$. A value for evenness approaching zero reflects large differences in abundance of species, whereas an evenness of one means all species are equally abundant. In the particular case that $s=N$, and hence all $n_{i}=1$, we find that $H^{\prime}=\ln (N), D^{\prime}=0, E=1$ and $F_{\alpha}=0$. If all $n_{i}$ are equal, say $n_{i}=n$, then $H^{\prime}=\ln (s), D^{\prime}=1-1 / s$, $E=1$ and $F_{\alpha}=((N-1) / n) / N$. On the other extreme, if there is one dominant species, say $n_{1}=N-s$ and all other abundances are small, i.e. $n_{2}=\cdots=n_{s}=1$, we find that $H^{\prime}=-((1-s) / N)$ $\ln ((1-s) / N), D^{\prime}=1-((1-s) / N)((1-s) /(N-1))$ and $E=-((1-s) / N) \ln ((1-s) / N) / \ln (s)$, whereas this distribution does not affect $F_{\alpha}$. 


\subsection{Sampling}

The study area was stratified into a grassland $(\mathrm{G})$ and a forest (F) stratum (Fig. 1). In both strata, systematic sampling was carried out, using circular plots. A GPS was used to position each plot centre. Sampling in G covered an area of approximately 162.5 ha of irregular shape and sampling in $\mathrm{F}$ an area of 94.5 ha of rectangular shape. Sampling in G was done at points with a spacing of $300 \mathrm{~m}$ along a transect of $1.89 \mathrm{~km}$ in the direction of the stretch of the area. Additional plots on the transect were sampled at a distance of $75 \mathrm{~m}$ from these plots to estimate variability for both longer and shorter distances. Data were also collected at $75 \mathrm{~m}$ intervals along transects perpendicular to the main transect at each of the $300 \mathrm{~m}$ points throughout $G$ to obtain an even spreading of plots within the stratum. When transects reached the edge of $\mathrm{G}$ at the grassland-forest transition zone, data were collected from one extra plot, the $\partial \mathrm{G}$ substratum. Within F, data were collected according to a grid with data separated by 75 and $300 \mathrm{~m}$. No sampling of a substratum comparable to $\partial \mathrm{G}$ took place in $\mathrm{F}$, because such a substratum did not exist.

At each plot all woody specimen were recorded. Species were grouped into three classes, according to the diameter at breast height $(\mathrm{dbh})$ : trees $(\mathrm{dbh}>10$ $\mathrm{cm})$, saplings $(10 \mathrm{~cm} \geq \mathrm{dbh}>2 \mathrm{~cm})$ and seedlings $(\mathrm{dbh} \leq 2 \mathrm{~cm})$. A minimum height of $20 \mathrm{~cm}$ was applied to avoid making mistakes in identifying the seedlings. Species were recorded in concentric circular plots of different sizes: $400 \mathrm{~m}^{2}$ for trees, $200 \mathrm{~m}^{2}$ for saplings and $50 \mathrm{~m}^{2}$ for seedlings. In total, 76 plots were sampled in G, 17 plots in the grassland edge substratum $\partial \mathrm{G}$ and 52 plots in F. These numbers are necessary to quantify spatial variability using variograms.

\subsection{Geostatistics}

Environmental data are likely to vary throughout a region. To quantitatively analyse this spatial variation we applied geostatistics (Chilès and Delfiner, 1999). A basic tool in geostatistics is the variogram, defined as

$\gamma_{j}(h)=\frac{1}{2} E\left[H_{j}^{\prime}(x)-H_{j}^{\prime}(x+h)\right]^{2}$

where $x$ and $x+h$ are two locations, separated by distance $h, E[\cdot]$ is the mathematical expectation and
$H_{j}^{\prime}(x)$ the Shannon index linked to location $x$. The variogram quantifies spatial variability of a variable as a function of the distance $h$ as it describes its spatial dependence. The variogram is determined by calculating mean squares of differences between observations that are separated by a distance approximately equal to $h$ for several values of $h$. Next, a model is fitted through these so-called empirical variogram values. Common variogam transitive models are:

- the exponential model $\gamma_{\mathrm{e}}(h)=C_{0}+C_{1}(1-\exp$ $(-h / b))$

- the Gaussian model $\gamma_{\mathrm{G}}(h)=C_{0}+C_{1}(1-\exp$ $\left.\left(-(h / b)^{2}\right)\right)$;

- the spherical model $\gamma_{\mathrm{S}}(h)=C_{0}+C_{1}\left(\frac{3}{2}(h / b)\right.$ $\left.-\frac{1}{2}(h / b)^{3}\right)$ for $h \leq b$ and $\gamma_{\mathrm{S}}(h)=C_{0}+C_{1}$ for $h>b$.

All models depend upon the nugget $\left(C_{0}\right)$, sill $\left(C_{1}\right)$ and range $(b)$ parameter. The nugget, the positive intercept of the variogram with the ordinate, represents unexplained spatially dependent variation or purely random variance. The sill is the value at which transitive variograms level out and the distance at which the levelling occurs is known as the range of spatial dependence. The exponential model describes attributes characterised by abrupt changes at all distances, the Gaussian model describes continuous, gradually varying attributes and the spherical model describes attributes with abrupt boundaries at discrete and regular spacings (range) but where the distance between the abrupt changes is not clearly defined (Burrough and MacDonell, 1998). For a measure of how well these models fit, the ratio of the sum of square deviations to the total sum of the square (SSD/SST) is used. The closer this ratio is to 0 the better the fit.

In studies on spatial variability, a central objective is to obtain maps from point observations. This requires optimal estimation of a value at unvisited locations, an activity commonly known as kriging (Isaaks and Srivastava, 1989). Kriging uses the variogram and only samples in the local neighbourhood of an estimation point. It, therefore, depends upon the quantified spatial variability of a variable and on the mean in a vicinity of an estimation point. Kriging also provides maps with standard deviations, displaying the variability as expressed by the prediction precision.

In this study, values of $H^{\prime}$ calculated for each plot individually were used in a geostatistical analysis to 
map woody species diversity in individual plots. In the statistical analysis, however, all the species occurring in each area were aggregated and a single value of $H^{\prime}$ was calculated as a measure of diversity in a plot. The results were compared with those of the other two biodiversity indices.

\section{Results}

\subsection{General}

Table 1 shows descriptive statistics for the number of species $(s)$ found in the G, F and $\partial \mathrm{G}$ strata. For the grassland stratum $\mathrm{G}, s$ is higher than for the forest stratum $\mathrm{F}$ or the grassland edge stratum $\partial \mathrm{G}$, for all three size classes. In G, saplings have the highest value for $s$. In $\mathrm{F}$ and $\partial \mathrm{G} s$ is highest for trees, whereas this value is lower in $F$ than in $\partial \mathrm{G}$. None of these differences is statistically significant $(\alpha=0.05)$. On a per plot basis, the lowest value for $s$ in G equals 0 (for the trees and saplings groups) and in $\mathrm{F}$ it equals 2; the highest value in $\mathrm{G}$ equals 16, whereas in $\mathrm{F}$ it equals 13 . The highest minimum number of species per plot and the highest maximum number of species per plot, however, occur in $\partial \mathrm{G}$. The $\mathrm{G}$ stratum has median values for $s$ between 4 and 6 and the $F$ stratum has the same median (7) for the three size classes. The $\partial \mathrm{G}$ substratum has higher median values for the three size classes (10-11) than G and F.

The $G$ stratum has a higher standard deviation for all the three size classes than the F stratum. This means that variability in $\mathrm{G}$ is higher than in $\mathrm{F}$ as far as number of species per plot is concerned. In the $\partial \mathrm{G}$ substratum standard deviations for all three size classes are lower than those for $G$, but higher than those for F.

\subsection{Overall biodiversity}

Table 2 shows the overall species diversity for the two main strata $\mathrm{G}$ and $\mathrm{F}$ as expressed by the Shannon index $H^{\prime}$ at the within plot scale. For all size classes, $H^{\prime}$ is higher in $\mathrm{G}$ than in $\mathrm{F}$ : $H^{\prime}$ ranges from 2.91 to 3.38 within $\mathrm{G}$ for the different size classes, whereas $H^{\prime}$ ranges from 1.87 to 2.32 in $\mathrm{F}$. In $\mathrm{G}, H^{\prime}$ is highest for the saplings group, then for the seedlings group and lowest for the trees group. In F, $H^{\prime}$ is highest for the trees group, then for the saplings group and lowest for the seedlings group. All differences in $H^{\prime}$ between the two strata $G$ and $F$ for the three size classes as well as the difference in $H^{\prime}$ between the two strata $G$ and $F$ as a whole, are statistically significant. We conclude, therefore, that overall biodiversity, as measured by the Shannon index $H^{\prime}$, is significantly higher in the grassland stratum $G$ than in the forest stratum $\mathrm{F}$.

\subsection{Plot-wise biodiversity}

Table 3 shows the descriptive statistics for $\bar{H}^{\prime}$, the mean of $H^{\prime}$, in $\mathrm{G}$ and $\mathrm{F}$ on a per plot basis. In $\mathrm{G}$, eight sub-plots occurred without trees and one sub-plot without saplings. These plots were disregarded as the calculations of $H^{\prime}$ in these cases gave undefined values. The $\bar{H}^{\prime}$ value in $\mathrm{G}$ is lower than that in $\mathrm{F}$ for all size classes, whereas in $\mathrm{G}$ the standard deviation is

Table 1

Descriptive statistics for the number of species $(s)$ in the three size classes in the two main strata $\mathrm{G}$ and $\mathrm{F}$ and the substratum $\partial \mathrm{G}$

\begin{tabular}{|c|c|c|c|c|c|c|}
\hline Stratum & Size class & No. of plots & $s$ & Median & Mean & Standard deviation \\
\hline \multirow[t]{3}{*}{$\mathrm{G}$} & Trees & 76 & 61 & 4 & 5 & 3.34 \\
\hline & Saplings & 76 & 74 & 6 & 7 & 4.13 \\
\hline & Seedlings & 76 & 65 & 5 & 6 & 3.57 \\
\hline \multirow[t]{3}{*}{$\mathrm{F}$} & Trees & 52 & 45 & 7 & 8 & 2.13 \\
\hline & Saplings & 52 & 44 & 7 & 7 & 2.41 \\
\hline & Seedlings & 52 & 38 & 7 & 7 & 2.20 \\
\hline \multirow[t]{3}{*}{$\partial \mathrm{G}$} & Trees & 17 & 59 & 11 & 10 & 3.30 \\
\hline & Saplings & 17 & 21 & 10 & 11 & 3.69 \\
\hline & Seedlings & 17 & 42 & 10 & 9 & 2.43 \\
\hline
\end{tabular}


Table 2

Overall species diversity using the Shannon index $\left(H^{\prime}\right)$ for the three size classes in the two main strata $\mathrm{G}$ and $\mathrm{F}$ and for the two main strata $\mathrm{G}$ and $\mathrm{F}$ as a whole (included is a $t$-test $(\alpha=0.05)$ to test for equality of the Shannon index between the two strata) ${ }^{\mathrm{a}}$

\begin{tabular}{|c|c|c|c|c|c|c|c|}
\hline Size class & Stratum & $N$ & $H^{\prime}$ & S.D. $\left(H^{\prime}\right)$ & $t$-Value & d.f. & $p$-Value \\
\hline \multirow[t]{2}{*}{ Trees } & G & 912 & 2.9065 & 0.050 & \multirow[t]{2}{*}{8.952} & \multirow[t]{2}{*}{1881} & \multirow[t]{2}{*}{$<0.05$} \\
\hline & $\mathrm{F}$ & 1107 & 2.3158 & 0.042 & & & \\
\hline \multirow[t]{2}{*}{ Saplings } & $\mathrm{G}$ & 1311 & 3.3778 & 0.033 & \multirow[t]{2}{*}{25.523} & \multirow[t]{2}{*}{2652} & \multirow[t]{2}{*}{$<0.05$} \\
\hline & $\mathrm{F}$ & 1383 & 2.0765 & 0.042 & & & \\
\hline \multirow[t]{2}{*}{ Seedlings } & $\mathrm{G}$ & 1911 & 2.9627 & 0.034 & \multirow[t]{2}{*}{24.144} & \multirow[t]{2}{*}{3843} & \multirow[t]{2}{*}{$<0.05$} \\
\hline & $\mathrm{F}$ & 2019 & 1.8686 & 0.030 & & & \\
\hline \multirow[t]{2}{*}{ Total } & G & 4134 & 3.3188 & 0.021 & \multirow[t]{2}{*}{37.123} & \multirow[t]{2}{*}{8620} & \multirow[t]{2}{*}{$<0.05$} \\
\hline & $\mathrm{F}$ & 4509 & 2.2075 & 0.021 & & & \\
\hline
\end{tabular}

${ }^{\mathrm{a}} N$ : total count, $s$ : number of species, d.f.: degrees of freedom.

larger than in F. Therefore, variability in $\mathrm{G}$ is higher than in $\mathrm{F}$ for $\bar{H}^{\prime}$. Differences are statistically significant for the trees and seedlings groups, but not for the saplings group. Comparison of standard deviations in the same table shows that differences in standard deviation between $\mathrm{G}$ and $\mathrm{F}$ are statistically significant for all three size classes.

Fig. 2 shows the spherical variogram models that best fit $H^{\prime}$ of the three size classes in the $\mathrm{G}$ and $\mathrm{F}$ strata. Only for the saplings in $\mathrm{F}$ a pure nugget effect is observed, corresponding to absence of spatial dependence. The nugget and the sill values in $\mathrm{F}$ are generally much lower than in G. This corresponds to the lower variability in $\mathrm{F}$ as compared to $\mathrm{G}$. All three size classes in $\mathrm{G}$ and the trees and seedlings size classes in $\mathrm{F}$ had a range, smaller than the maximum sampling distance $(1887 \mathrm{~m})$. This allowed to observe the full range of spatial dependence within the sampled areas. Ranges in $\mathrm{G}$ were higher than in $\mathrm{F}$ for both the trees and the seedlings. This illustrates that spatial dependence is generally larger in $\mathrm{G}$.

Fig. 3 shows the spatial distribution of $H^{\prime}$ for the three size classes in the $G$ and $F$ strata, without the saplings for $\mathrm{F}$ for which absence of a structured variogram did not allow any mapping. Grassland shows a general decrease in species abundance and richness from the eastern to the western part and to some extent also from the centre towards its northern and southern edges and into the patch in the south. The centre of the eastern part and the narrow corridor connecting the eastern and western parts show relatively high species abundance and richness. Stratum F does not show any clear pattern but only local deviations from the overall mean. Notice, e.g., that the differences for $H^{\prime}$ for trees within $\mathrm{F}$ is extremely small (from 1.63 to 1.73 ).

Table 3

Descriptive statistics for the plot-wise species diversity $\bar{H}^{\prime}$ of the Shannon index $\left(H^{\prime}\right)$ in the three size classes in the two main strata $\mathrm{G}$ and $\mathrm{F}$ (included are a $t$-test for equality of means and an $F$-test for equality of standard deviations $(\sigma)$, using a 0.95 confidence level with null hypothesis $H_{0}$ and alternative hypothesis $H_{1}$ in the table heading)

\begin{tabular}{|c|c|c|c|c|c|c|c|}
\hline \multirow[t]{2}{*}{ Size class } & \multirow[t]{2}{*}{ Stratum } & \multirow[t]{2}{*}{$\bar{H}^{\prime}$} & \multirow[t]{2}{*}{ S.D. $\left(\bar{H}^{\prime}\right)$} & \multicolumn{2}{|c|}{$H_{0}: \mu_{\mathrm{G}}=\mu_{\mathrm{F}}, H_{1}: \mu_{\mathrm{G}}<\mu_{\mathrm{F}}$} & \multicolumn{2}{|c|}{$H_{0}: \sigma_{\mathrm{F}}=\sigma_{\mathrm{G}}, H_{1}: \sigma_{\mathrm{F}} \neq \sigma_{\mathrm{G}}$} \\
\hline & & & & $t$-Value & $p$-Value & $F$-Value & $p$-Value \\
\hline \multirow[t]{2}{*}{ Trees } & G & 1.221 & 0.630 & \multirow[t]{2}{*}{-4.82} & \multirow[t]{2}{*}{$<0.001$} & \multirow[t]{2}{*}{4.21} & \multirow[t]{2}{*}{$<0.001$} \\
\hline & $\mathrm{F}$ & 1.679 & 0.307 & & & & \\
\hline \multirow[t]{2}{*}{ Saplings } & G & 1.419 & 0.640 & \multirow[t]{2}{*}{-0.31} & \multirow[t]{2}{*}{0.380} & \multirow[t]{2}{*}{2.91} & \multirow[t]{2}{*}{$<0.001$} \\
\hline & $\mathrm{F}$ & 1.447 & 0.375 & & & & \\
\hline \multirow[t]{2}{*}{ Seedlings } & G & 1.191 & 0.644 & \multirow[t]{2}{*}{-2.55} & \multirow[t]{2}{*}{0.006} & \multirow[t]{2}{*}{3.10} & \multirow[t]{2}{*}{$<0.001$} \\
\hline & $\mathrm{F}$ & 1.419 & 0.365 & & & & \\
\hline
\end{tabular}


Forest
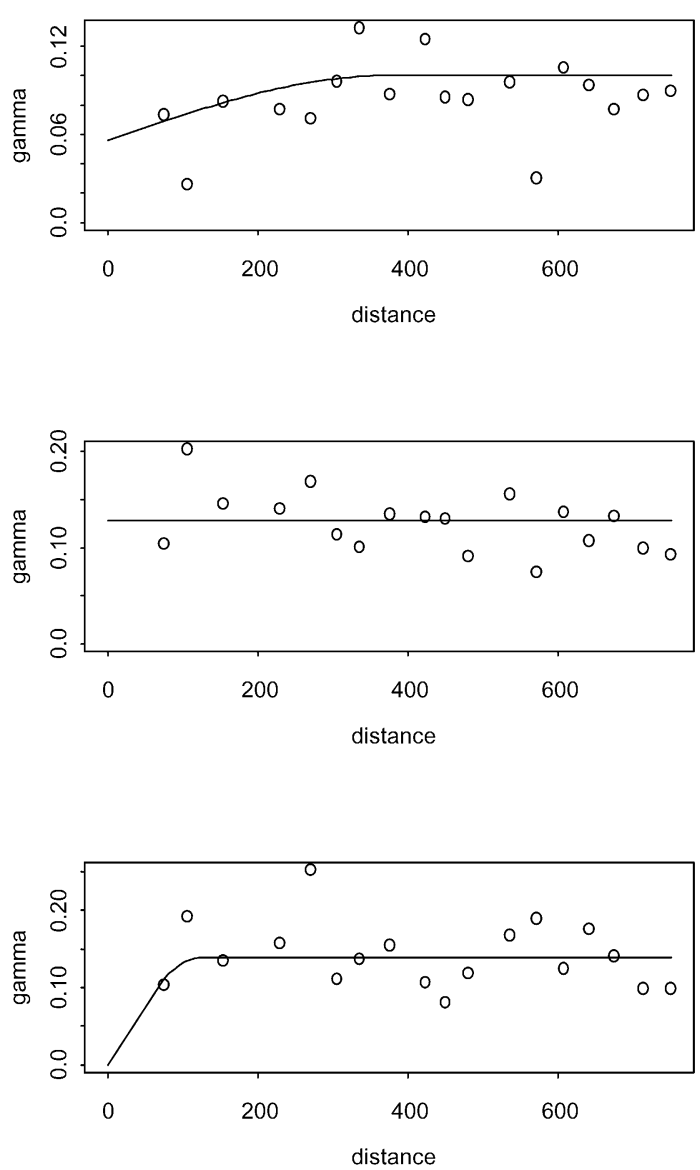

\section{Grassland}
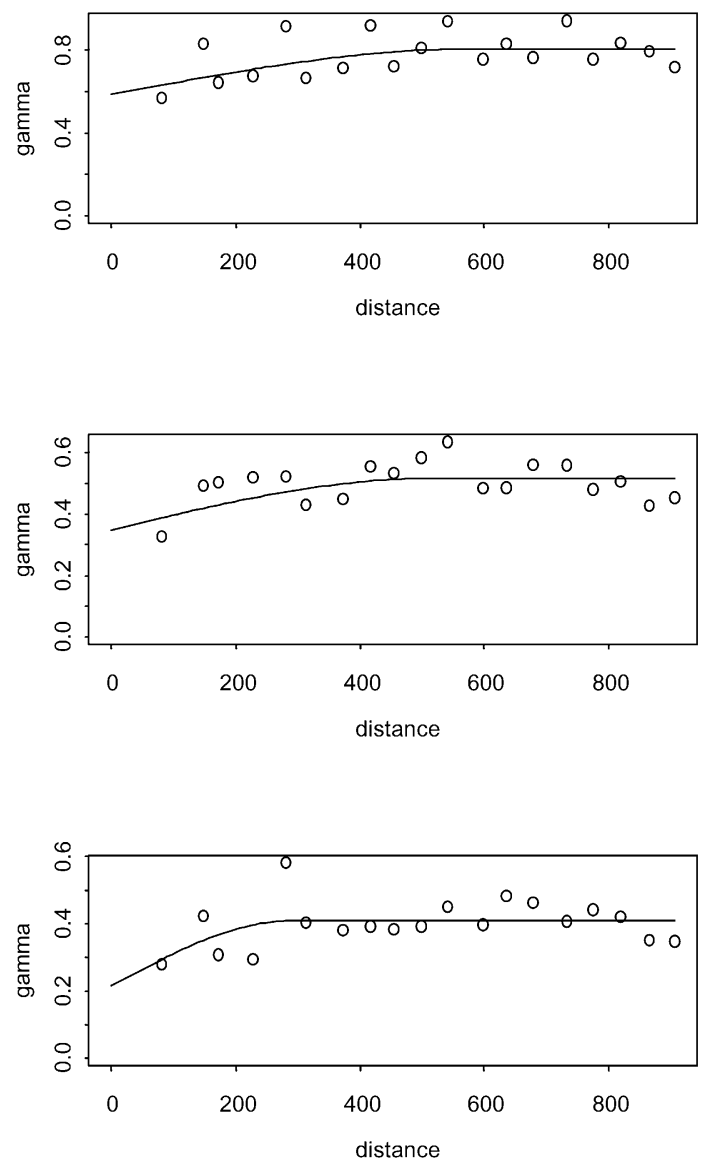

Fig. 2. Spherical variogram models for the Shannon index $H^{\prime}$ for trees, saplings and seedlings in the forest and grassland strata (all distances are expressed in meters).

\subsection{Comparison with other biodiversity indices}

We compared the results of the Shannon index with those of Simpson index $D^{\prime}$, the Shannon-Wiener index $E$ and Fisher's $\alpha\left(F_{\alpha}\right)$ for the saplings group. Similar results could have been obtained for trees and seedlings. Table 4 lists variogram parameters of the best fitting models. In $\mathrm{G}$, the exponential model gives the best fit for the Simpson index $D^{\prime}$, the Gaussian model for the Shannon-Wiener index $E$, and the spherical model for Fisher's $\alpha$. In F, the Gaussian model gives the best fit for both $D^{\prime}$ and $E$, whereas the spherical model gives the best fit for $F_{\alpha}$. Variability in $\mathrm{F}$ is generally much lower than in $\mathrm{G}$, as appears from the lower nugget and sill parameters. F and G both show a relatively low spatial dependence, with ranges in all cases smaller than the maximum sampling distance. Fig. 4 shows maps for the diversity indices within the grassland stratum. A relatively higher species dominance $D^{\prime}$ and evenness $E$ occur in the western part of $G$ and a relatively lower species dominance and evenness in the eastern part. This well agrees with results obtained by the Shannon index $H^{\prime}$. Clearly, these three biodiversity indices show basically the same picture to describe and quantify species biodiversity. Fisher's $\alpha$, though, shows an entirely different pattern, with patches of high biodiversity and an almost isolated spot with low biodiversity. 


\section{Forest}
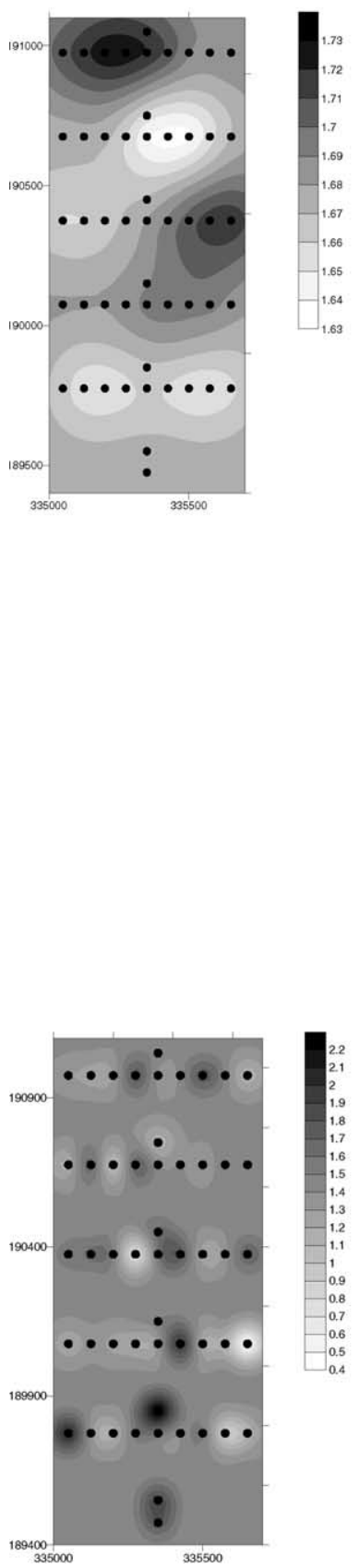

\section{Grassland}

ֻ
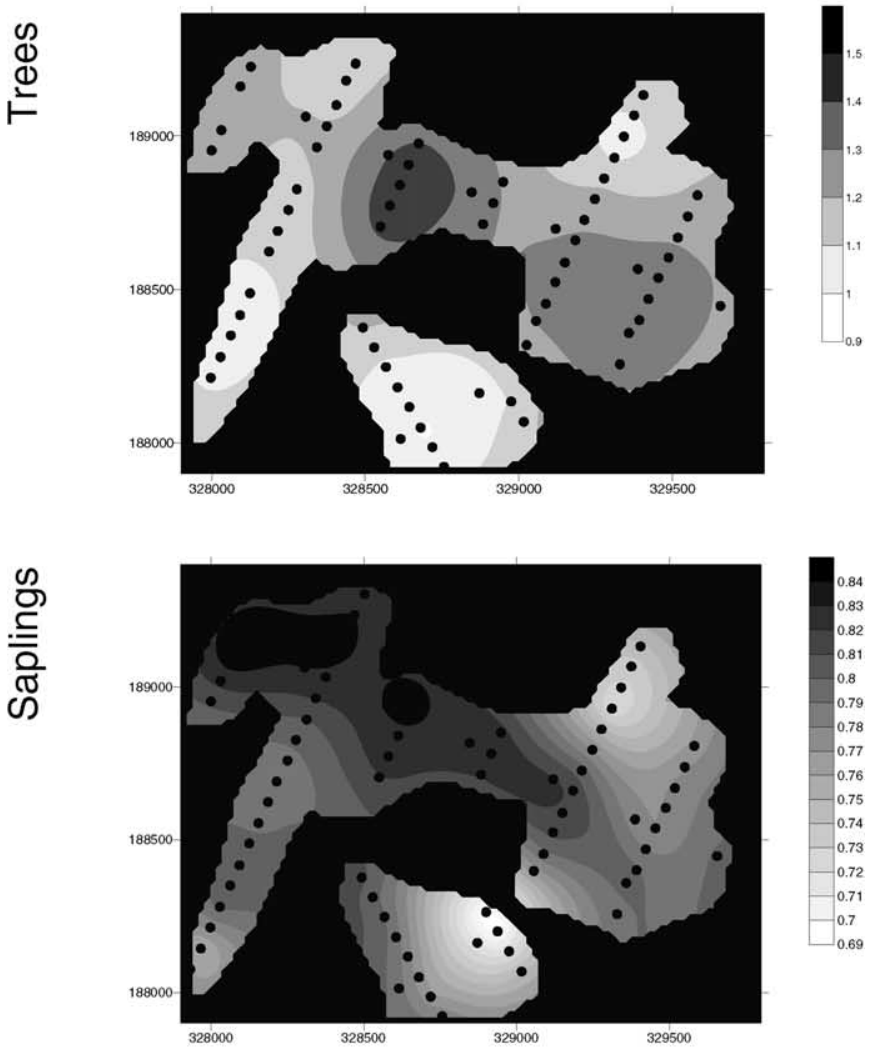

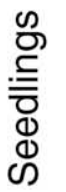

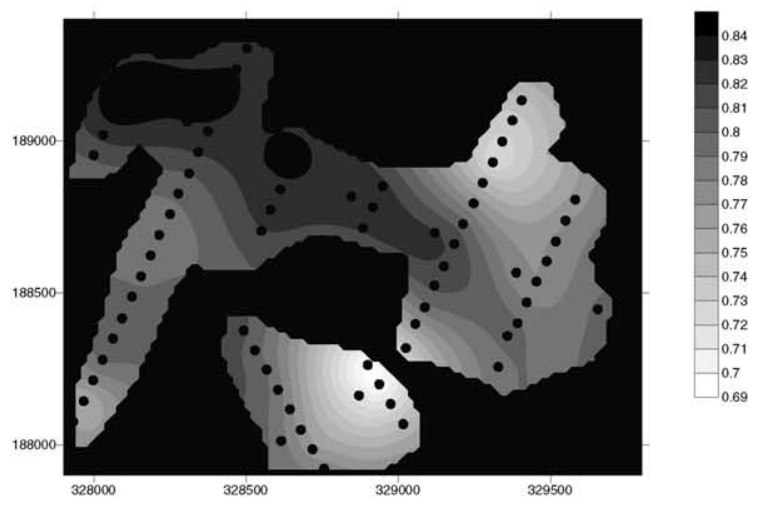

Fig. 3. Distribution of the Shannon biodiversity index $H^{\prime}$ for trees, saplings and seedlings in the grassland and forest strata. No map could be obtained for saplings in $\mathrm{F}$ because of the lack of spatial variability. 
Table 4

Variogram parameters for the Simpson $(D)$, Shannon-Wiener $(E)$ and Fisher's $\alpha\left(F_{\alpha}\right)$ indices for saplings in the grassland and forest strata

\begin{tabular}{llllll}
\hline Stratum & Index & Model & Nugget & Sill & Range \\
\hline $\mathrm{G}$ & $D^{\prime}$ & Exponential & 0.044 & 0.0632 & 430 \\
& $E$ & Gaussian & 0.0413 & 0.426 & 0.0147 \\
\\
& $F_{\alpha}$ & Spherical & 0.0103 & 0.0238 & 9208.4 \\
$\mathrm{~F}$ & $D^{\prime}$ & Gaussian & 0.0146 & 0.0125 & 613 \\
& $E$ & Gaussian & 0.00896 & $5.08 \times 10^{-5}$ & 148.5 \\
\hline
\end{tabular}

\section{Shannon's H'}

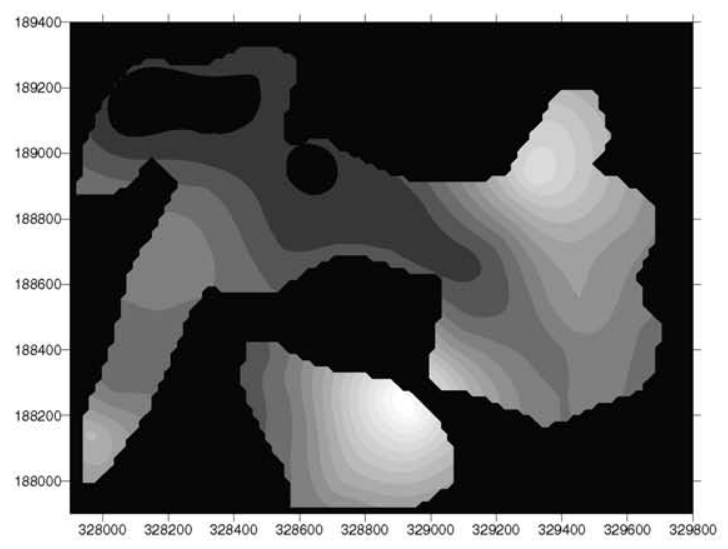

Shannon-Wiener's E

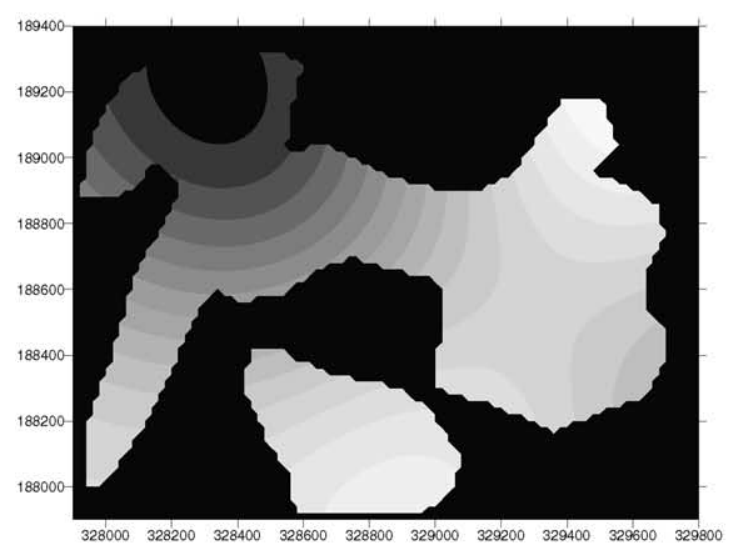

\section{Simpson's D}

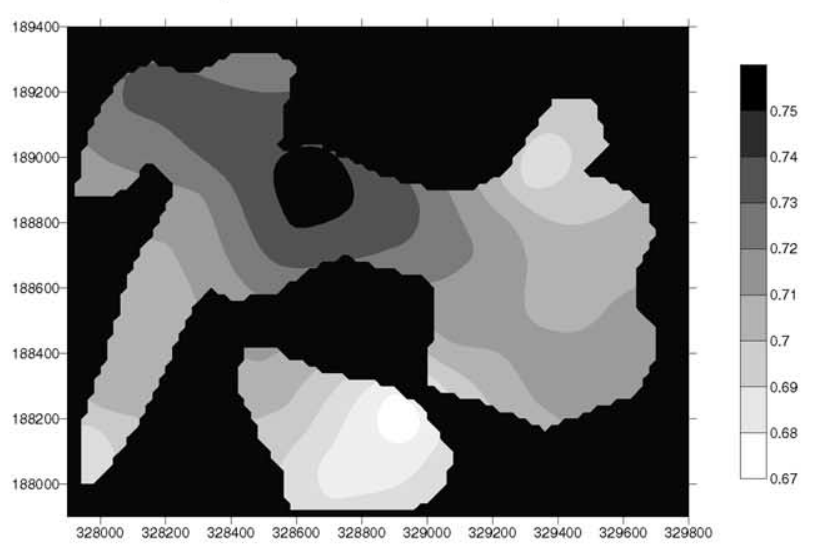

Fisher's alpha

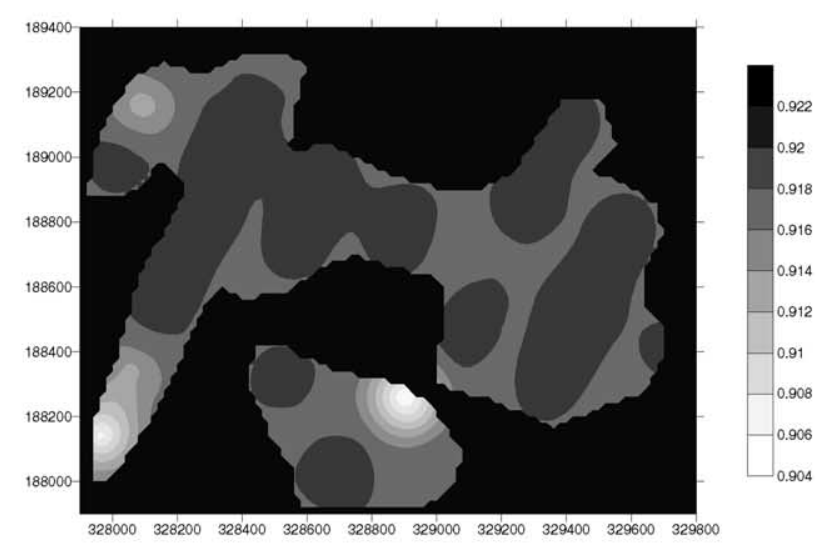

Fig. 4. Distribution of biodiversity based on the Shannon index (upper left), the Simpson index (upper right), the Shannon-Wiener index (bottom left) and Fisher's $\alpha$ (bottom right) for saplings in grassland. Similar pictures could have been obtained for the forest stratum and for different size groups. 


\section{Discussion}

We first discuss biodiversity in grassland. Fig. 3 shows decreasing species abundance and richness for trees from the eastern part to the western part and to the north and the south from the centre of the eastern part. For saplings and seedlings, it shows an irregular pattern of areas with both very low and very high species abundance and richness. The western part of the area (i.e. the area west of the corridor) and the isolated part in the south are currently burned on an annual basis. These parts are dominated by tree species such as Combretum collinum, Acacia hockii, Acacia seyal, Terminalia glaucescens and Annona senegalensis, which have characteristics that protect them from fire, such as thick bark. These parts also contain many saplings and seedlings of Vernonia amygdalina, a species easily destroyed by fire, but with the capacity to regenerate rapidly. The area east of the corridor and the corridor itself have not experienced burning for at least 3 years, as was ascertained by interviewing the hunting people. These parts do not show dominance of any particular species, but rather comprise a mix of grassland and more typical 'forest' species. Trees in the forest and the forest edge act as a seed source in addition to trees in the grassland. Saplings and seedlings of the forest and forest edge species that are without characteristics to protect them from fire have been able to establish themselves in the absence of a recent fire. Species typically found in these parts of the grassland are colonisers such as Albizia zygia, Croton megalocarpus, Maesopsis eminii, Caloncoba schweinfurthii, Funtumia elastica and Dombeya mukole. The areas of low and high species abundance and richness for saplings and seedlings do not exactly coincide, but to some extent locations are similar. Factors governing the location of these areas could be related to differences in soil conditions (depth, fertility, moisture), in intensity of fires and in seed dispersal mechanisms, that may or may not favour colonisation.

Next we consider biodiversity in the forest. Fig. 3 shows several areas of relatively lower and higher species diversity for trees, a relatively small decrease in species diversity from south-east to north-west for saplings and again a number of areas of relatively lower and higher species diversity for seedlings. The forest plots usually contain many species and little variation exists between plots. In general, no areas with very low species diversity or dominance of just a few species occur. The forest as a whole shows that the species Celtis milbraedii, Cynometra alexandrii, Lasiodiscus milbraedii and Rinorea ilicifolia occur in considerably larger numbers than other species (comprising, respectively, 72,78 and $82 \%$ of all trees, saplings and seedlings). The first two species are typical upperstorey and the last two typical understorey species. These species are usually accompanied by several other species. The occurrence of areas of relatively lower and higher species abundance and richness for trees and seedlings seems to be without any apparent pattern and is likely to be related to the localised dynamics of seed dispersal and the openingup of the forest canopy through the falling of big, usually over-mature, trees.

This study shows that overall species diversity in the grassland area is significantly higher than in the forest area. This agrees with observations made by Stott et al. (1990), who observed that most species-rich grasslands in south-east Australia have been ungrazed and frequently burned for decades.

An important factor to explain the high overall species diversity in $G$ is the variation in disturbance regimes that currently exist in this area, with frequent fires in some parts and less frequent fires in other parts. Important in this respect is that $\mathrm{G}$ is surrounded by forest, which allows for the colonisation of the grassland by species more typically belonging to forest or forest edge. The lowest overall species diversity occurs for trees. In the study area, species can grow into tree size provided: (a) they are fireresistant and (b) they have not been subjected to a fire for a while. Whereas the first condition is clearly met by a number of species currently present in good numbers in especially the western and southern parts of the grassland, the second condition is probably not yet or not yet sufficiently met. Maybe the last fire in the eastern part of the grassland and the corridor is still too recent for some of the species present there to have managed to grow into tree size in good numbers. In that case a longer absence of fire in these parts of the grassland may still increase the overall species abundance and richness in the trees group for some time to come. The highest overall species diversity occurs for saplings. Especially, in this group, a mixture exists of individuals of species, that are resistant to fires 
and that have survived previous fires, and individuals of species that are not or less resistant to fires, but that have not been subjected to a fire recently.

Clearly, there is some ambiguity in the results that show a significantly higher biodiversity in $\mathrm{G}$ than in $\mathrm{F}$ if the standard theory on biodiversity indices is taken into account. Species diversity on a per plot basis gives a different picture. Average species diversity in $\mathrm{F}$ is significantly higher than in $\mathrm{G}$, at least for trees and seedlings. This is of considerable interest, as it shows that a spatial analysis may lead to different conclusions on biodiversity than an overall analysis. The statistical significance, however, is strong and wellsupported by the analysis. An explanation is that the various disturbance regimes in $\mathrm{G}$ lead to higher numbers of species (both typical grassland as well as typical forest species), to lower and higher extremes in plot-wise species diversity and to a higher variation in plot-wise species diversity. Eventually, however, this may lead to lower average species diversity on a per plot basis as compared to the forest. The general picture for $\mathrm{F}$, emerging from field observations and maps, produced in this study, is that of a relatively homogeneous, low contrast, landscape, with only some localised disturbances (canopy gaps through falling of trees). Species diversity, whether considered for the forest area as a whole or on a per plot basis, is high.

Looking at developments in the less frequently burned parts of the grassland, an interesting question would be: what will happen to the grassland when burning would stop completely? Paterson (1991) suggests that the grassland would eventually be converted to forest. This was confirmed as well by a study of aerial photographs from 1950 to 1988 . When describing and quantifying species diversity in areas, statistical analysis alone is not sufficient, as it does not take care of spatial variation, i.e. variation linked to locations (Acharya et al., 2000). This is where geostatistical analysis, in particular, when it is combined with a geographical information system proved to be useful in this study. The geostatistical analysis, e.g., showed exactly where areas of high and low species diversity occurred in G. This then enabled us to make a link with the information about the burning regimes in this area. It also enabled us to identify some spots of relatively higher and lower species diversity within the seemingly very homo- geneous forest area. Such information is important in understanding the mechanisms of the spatial distribution of biodiversity and its variation, and will enable conservationists to define location and size of biodiversity conservation areas.

\section{Conclusions}

On the basis of the study we reach the following conclusions:

1. Biodiversity on a per plot basis is higher in a grassland stratum subject to burning than in a tropical forest stratum. The main reason appears to be the variation in fire disturbance regimes in the burned area, which enables a variety of species to co-exist in that area.

2. The use of several indices proved useful to quantify existing biodiversity. The study did not show that any of the indices used was superior to the others.

3. Statistical and geostatistical methods are useful to describe, test and compare quantitative statements on biodiversity. Statistical methods proved that visual inspection could be confirmed and tested on its significance, whereas geostatistical methods showed how the amount of spatial variation differed between grassland and forest.

\section{References}

Acharya, B., Bhattarai, G., De Gier, A., Stein, A., 2000. Systematic adaptive cluster sampling for the assessment of rare tree species in Nepal. For. Ecol. Mgmt. 137, 65-73.

Burrough, P.A., MacDonell, R.A., 1998. Principles of Geographical Information Systems. Oxford University Press, Oxford.

Chandler, C., Cheney, P., Thomas, P., Trabaud, L., Williams, D., 1983. Fire in Forestry, Vol. 1. Forest Fire Behavior and Effects. Wiley, New York.

Chilès, P., Delfiner, P., 1999. Geostatistics: Modelling Spatial Uncertainty. Wiley, New York.

Connell, J.H., Slatyer, R.O., 1977. Mechanisms of succession in natural communities and their role in community stability and organisation. Am. Nat. 111, 1119-1144.

Dallmeier, F., 1998. Measuring and monitoring forest biodiversity: the SI/MAB model. In: Bachmann, P., Köhl, M., Päivinen, R. (Eds.), Proceedings of the Conference on Assessment of Biodiversity for Improved Forest Planning, Monte Verità, Switzerland, October 7-11, 1996. Kluwer Academic Publishers, Dordrecht, pp. 15-29. 
Forman, R.T.T., Godron, M., 1986. Landscape Ecology. Wiley, New York.

Heusèrr, M.J.J., 1998. Putting diversity indices into practice. Some considerations for forest management in The Netherlands. In: Bachmann, P., Köhl, M., Päivinen, R. (Eds.), Proceedings of the Conference on Assessment of Biodiversity for Improved Forest Planning, Monte Verità, Switzerland, October 7-11, 1996. Kluwer Academic Publishers, Dordrecht, pp. 171-180.

Howard, P.C., Viskanic, P., Kigenyi, F.W., 1998a. Biodiversity assessment for conservation planning in Uganda's forests. In: Bachmann, P., Köhl, M., Päivinen, R. (Eds.), Proceedings of the Conference on Assessment of Biodiversity for Improved Forest Planning, Monte Verità, Switzerland, October 7-11, 1996. Kluwer Academic Publishers, Dordrecht, pp. 263-271.

Howard, P.C., Viskanic, P., Davenport, T.R.B., Kigenyi, F.W., Baltzer, M., Dickinson, C.J., Lwanga, J.S., Matthews, R.A., Balmford, A., 1998b. Complementarity and the use of indicator groups for reserve selection in Uganda. Nature 394, 472-475.

Isaaks, E.H., Srivastava, R.M., 1989. An Introduction to Applied Geostatistics. Oxford University Press, New York.

Kent, M., Coker, P., 1992. Vegetation Description and Analysis: A Practical Approach. Wiley, New York.

Langoya, C.D., Long, C., Grundy, I., Le Breton, G., Mejia, R., Benitez, R., 1998. Local communities and ecoutourism development in Budongo Forest Reserve, Uganda. ODI, London.

Magurran, A.E., 1988. Ecological Diversity and Its Measurement. Croom Helm, London.
McDougall, K.L., 1989. The re-establishment of Themeda triandra (Kangaroo grass): implication for the restoration of grassland. Arthur Rylah Institute for Environmental Research Technical Report Series No. 89. Department of Conservation, Forests and Lands, Melbourne.

Morgan, J.W., Lunt, I.D., 1999. Effects of time-since-fire on the tussock dynamics of a dominant grass (Themeda triandra) in a temperate Australian grassland. Biol. Conserv. 88, 379386.

Oesterheld, M., Loreti, J., Semmartin, M., Paruelo, J.M., 1999. Grazing, fire and climate effects on primary productivity of grasslands and savannas. In: Walker, L.R. (Ed.), Ecosystems of the World 16. Ecosystems of Disturbed Ground. Elsevier, Amsterdam, pp. 287-306.

Paterson, J.D., 1991. The ecology and history of Uganda's Budongo Forest. For. Conserv. Hist. 35, 179-186.

Parviainen, J., Päivinen, R., 1998. Information needs for biodiversity assessment derived from international forestry discussions. In: Bachmann, P., Köhl, M., Päivinen, R. (Eds.), Proceedings of the Conference on Assessment of Biodiversity for Improved Forest Planning, Monte Verità, Switzerland, October 7-11, 1996. Kluwer Academic Publishers, Dordrecht, pp. 63-70.

Reid, W.V., McNeely, J.A., Tunstall, D.B., Bryant, D.A., Winograd, M., 1993. Biodiversity Indicators for Policy-makers. World Resources Institute, Washington, DC.

Stott, P.A., Goldammer, J.G., Werner, W.L., 1990. Fire in the Tropical Biota. Springer, Berlin. 